\title{
Retinoids in Oral Diseases: An Enigmatic Role in Chemoprevention
}

\author{
Cheshta Walia ${ }^{1 *}$ and Sudip Roy ${ }^{2}$ \\ ${ }^{1}$ Department of Oral and Maxillofacial Pathology, Buraydah Private dental College, Buraydah, Saudi Arabia \\ ${ }^{2}$ Department of Orthodontics \& Dentofacial Orthopedics, Buraydah Private dental College, Buraydah, Saudi Arabia
}

Received: May 30, 2016; Accepted: July 02, 2016; Published: July 22, 2016

*Corresponding author: Cheshta Walia, Department of Oral and Maxillofacial Pathology, Buraydah Private dental College, Buraydah, Saudi Arabia, 31717; Tel no: +966 537868090; E-mail: cheshtawalia@gmail.com

\begin{abstract}
Carcinogenesis is a complex disease which involves environmental and genetic factors as a predisposing cause that bring alterations in the microstructure of the cell. Vitamin A is considered as an essential micronutrient whose role is extensively known in physiologic and elusive in pathological state associated with chemopreventive and therapeutic modalities. Retinoids, form of Vitamin A, have been known to suppress cancers related to breast, lung, bladder, prostrate, blood and to some extent the cancers of oral cavity. Successful results have been observed and reported in certain types of leukemia but its role in oral premalignant and malignant lesions are still in its premature state. Suggested school of thoughts says that Retinoids act through receptors like RAR/RXR to form ligands which affect transcription of gene that controls abnormal proliferation, angiogenesis and metastasis. Various immunotherapeutic modalities focus on the receptors, receptor binding or receptor ligands for the better prevention and prognosis of the disease. The prognosis of the disease depends on the invasive extent and ability to metastasis to distant organ but the major limitation that prevail the use of drugs is to develop resistance against the respective receptors. The present review focuses on the physiologic, epigenetic and molecular role of Vitamin A in few of the lesions affecting the oral cavity.
\end{abstract}

Keywords: Carcinogenesis; Retinoids; Receptors; Resistance; Chemoprevention

\section{Introduction}

The head and neck cancer is major area of concern worldwide with the increasing incidence and high mortality rate. Oral cancer is a $6^{\text {th }}$ major cancer affecting head and neck region globally with 5 year survival rate in approximately $50 \%$ patients [1]. Genomic, proteomic, lipidomic and basic advancement has unraveled many molecular aspects of cell which influences cellular differentiation, apoptosis, angiogenesis and metastasis. The pathogenesis suggests that neoplastically altered cell acquire self-renewal capacity owing to multiple level mutations causing disruption of molecular pathways. One among these aberrations is alterations of Retinoid Acid Receptor $\beta$ (RAR $\beta$ ) expression in various carcinomas like squamous cell carcinoma, breast carcinoma, leukemia etc [2].

Chemoprevention is an important aspect which to some extent helps to repair and reverse the cellular defects thereby preventing initiation and progression into tumorigenesis. It plays a key role during early stages of lesions to prevent or minimize the lethal effects and/or progression of disease process. In 1976, Michael B. Sporn identified the role of Vitamin A in prevention of diseases setting the new path of research in chemoprevention [3].

The Vitamin A consists of retinoid molecule family in the form of retinol, retinal, retinoic acid and other pro- vitamin A like carotenoids. It is readily available in vegetable and animal sources such as cod liver oil, eggs, butter, milk, carrot, spinach etc, as a precursor to retinol. Liver is the store house from where the retinol undergoes esterification to its active forms and distributed to the body parts through blood. It binds to cell membrane receptor like rexinoid receptor (RXR) and its isoforms $(\alpha, \beta, \gamma)$ which allow passage of retinol in the cell as Retinoic Acid (RA) or its derivatives like All Trans RA (ATRA), 9 cis RA and 13 cis RA. Inside the cell, RA further binds to Retinoic Acid Receptor (RAR) and its isoforms $(\alpha, \beta, \gamma)$ along with hormone binding receptors to allow transcription of genes [4].

The molecular modification of vitamin A, aids a role in expression of growth factors, differentiation of cells, immunity, reproduction and repair of epithelial tissue. In oral tissue, deficiency of endogenous vitamin A may cause defective tooth formation and hypo/dyskeratosis of oral mucosa due to dysregulation caused during development of dental lamina and oral ectoderm respectively [5,6].

Although it is widely believed that retinoids have the potential to control an imbalance at cellular level but the exact mechanism is yet unknown. 9 cis RA, 13 cis RA and ATRA are the commonly known retinoids which readily bind to receptor and its ligands, to influence the progression or regression of mutated cell in cancers. Recently the use of retinoids has become an emerging field which targets to reverse the cytotoxic effects of mutated cancer cell at the molecular level [7].

This article attempts to review and present the chemotherapeutic effects of vitamin A and its analog as preventive measure in oral premalignant lesions and oral cancer. 


\section{Molecular Pathways}

The mechanism by which vitamin A influences head and neck cancer has been extensively revised in literature. ATRA and 9 cis RA act as ligand dependent transcription factor by binding RAR / RXR subfamily to form heterodimers or homodimers (RAR/RAR). Heyman, et al. stated that ATRA and 9 cis RA have equal potentiality to activate RAR while 9 cis RA has 50 times more potentiality than ATRA to activate RXR [8]. Blomhoff, et al. expressed the role of intracellular transportation of RA by binding to cytosolic Cellular Retinoic Acid Binding Protein I and II (CRABP) [9].

Receptor-ligand complex further downstream effectors by binding to Retinoic Acid Response Elements (RAREs/RXREs) located in 5 / region of RA downstream gene. The ligand available in the cell is another regulatory factor which guides the RA to its target to bring conformational changes and activate gene transcription. Once binding is completed, two pathways are suggested to be involved which determine the effects of Vitamin A on tissues

(a) Genomic or classical pathway,

(b) Non-classical pathway.

Cell differentiation, cell arrest, and apoptosis are the features of classical pathway. Also in classical pathway, RA function through involvement of Nuclear Factor (NF- $\kappa \beta$ ) [10], Interferon (INF- $\gamma$ ) [11], Vascular Endothelial Growth Factor (VEGF) [12], Tumorogenesis Growth Factor (TGF- $\beta$ ) [13]. In non classical pathway RA will form heterodimers with Estrogen Receptor (ER$\alpha$ ), Activating Protein (AP-1) receptor, vitamin D receptor. The classical and non classical pathway functions quite differently where, classical pathway has capacity to allow gene transcription to prevent tumorogenesis by cellular differentiation and apoptosis while the non classical pathway makes cancer cell non responsive to RA treatment by inactivating the receptor efficiency. Vander berg reported that breast cancers which are Estrogen dependent for proliferation have better outcomes with retinoids due to higher sensitivity to ER $[14,15]$.

The limiting factors as outlined by Bastein, et al. states that regulatory functions of Vitamin A is dependent on its intracellular absorption, concentration, duration and specificity. Availability is also related to synthesis, uptake and degradation of retinoids at the targeted tissue site [16].

\section{Protective role of Retinoids}

The retinoids have distinctive functions in physiological and pathological state of human body. It controls gene expression which influences enzymes, proteins, hormones and growth factors to bring about series of signal modification that maintain the transcriptional activity between the disease and normal being.

\section{Retinoids as Immunomodulators:}

Retinoid's role in maintaining immunity of the body is an extensive well known phenomenon. Physiologically, Vitamin A levels are regularly maintained to protect host from daily harmful stimuli. With various studies, it is evident that on one side, $\mathrm{T}_{\mathrm{h}} 17$ helps to protect the host from undesirable bacterial and fungal stimuli by acting as mediator responsible for initiating auto immune responses. On the other hand, $\mathrm{T}_{\text {reg, }}$ member of FOXP3+ family is known for suppressing massive effector $\mathrm{T}$ cell activation by producing interleukins $[17,18]$. The overall effect causes improved resistance of host towards auto immune disease. RA directly influence FOXP3 $+\mathrm{T}_{\text {reg }}$ cells in regulating the ratio between $\mathrm{T}_{\mathrm{h}} 17$ and $\mathrm{T}_{\text {reg }}$ to prevent any untoward body's reaction to inflammatory responses as in auto immune diseases where the harmony between the $\mathrm{T}$ Helper cell $\left(\mathrm{T}_{\mathrm{h}}\right.$ cells) and Regulatory $\mathrm{T}$ cell $\left(\mathrm{T}_{\text {reg }}\right)$ population is disrupted $[17,18]$. In recent days, ATRA is being used to treat autoimmune disease like SLE and type 1 diabetes due to its effects on reducing anti DNA antibodies $[19,20]$. Constant elevated level of RA primes an example for resistance of body to antigenic load in elderly patients [21]. Gupta and Sansoni, et al. stated that age related changes are linked to the antigenic load with progressive increase in effector/cytotoxic CD8+ T cell population producing IL-2, IFN- $\gamma$ and TNF $\alpha[17,18]$.

Szondy, etal. observed that vitamin A aids in regulating healthy reserve of $\mathrm{T}$ lymphocyte by allowing maturation of normal cells and selective apoptosis of defective cells which tightly regulate body's immune circuit. He studied that lymphocyte originating from thymus in $\mathrm{T}$ cell hybridomas generate $\mathrm{T}$ Cell Receptors (TCRs) that carry an important signal for maturation of $\mathrm{T}$ cell [22]. After reaching the periphery, $\mathrm{T}$ lymphocyte survival depends upon antigen expression in acute diseases which increase IL-2 and bcl- $\mathrm{X}_{\mathrm{L}}$ expression which further prevents apoptosis in the cell $[23,24]$.

Iwata and yang, et al. mentioned that retinoids usually act in a synergistic pattern to enhance glucocorticoid induced death and decrease TCR-mediated death of thymocytes and T cell hybridomas $[27,28]$. Yang, et al. also mentioned the role of ATRA to inhibit virus induced T cell death in HIV positive patients by downregulating fasL production, thereby alter the ratio of CD8+ and CD4+ T cell $[29,30]$.

\section{Tumor suppressive activity}

Several crosstalk occur which strictly regulate the interaction of retinoid and its receptors to downstream the proliferating tumor cells. They either allow the abnormally proliferative cells to differentiate or undergo apoptosis. Observation suggests that in malignant cases, RAR- $\beta$ expression is either lost or masked resulting in reduced intracellular binding of RA [31,32]. This could also be evident due to increased metabolism of RA, which is dependent on specific members of cytochrome (CYP 450) that maintains the concentration of RA in the cell, for specific time period. The role of CYP super family members is initiated during embryonic development and continues throughout the life. Ross, et al. proposed that CYP 26 enzymes may extend the half-life of RA intra-cellularly thereby prevents the oxidative stress on the cell that promote oncogenesis [33]. In vivo, up regulation of CYP 
26 mRNA expression is seen in all cancer cells and tumors. The evidence suggests that expression of CYP 26 mRNA is seen as an inverse relation to concentration of RA in cells and tissues. Chang, et al. observed the similar findings in barrett's dysplasia and adenocarcinoma of esophagus [34]. Therefore, the link between RA signal and carcinogenesis may be established via expression of enzymes of CYP 26 super family. Ross et al observed that antiproliferative property of retinoids is diminished by enhanced expression of CYP 26 that suppressed cellular response to anoikis and control anchorage independent growth [33].

\section{Role in Apoptosis}

Disrupted expression of NF-K $\beta$ in carcinomas is an important association to determine the anti apoptotic activity of tumors. NF$\kappa \beta$ expression is usually seen in bacterial or viral stimuli leading to inflammation. In oncogenesis, increase expression of NF-K $\beta$ corresponds to increase resistance of the tumor to treatment. Retinoids act through mitochondrial pathway to release cytochrome $\mathrm{c}$ into the cytosol which allow caspase pathway to activate and cause apoptosis. Chen $\mathrm{Z}$ and Di Donato, et al. reported that expression of NF-K $\beta$ is seen due to phosphorylation of IKB (inhibitor of kappa beta) by IKB Kinase (IKK) which allows poly ubiquitination and proteasome dependent degradation of its inhibitors. Following this, the entry of NF-K $\beta$ into the nucleus allows various gene transcriptions to prevent apoptosis. IKK is the regulator of NF-K $\beta$ pathway involved in proliferation and differentiation of epidermal keratinocytes. Retinoids or Retinoids Related Molecules $\left(\mathrm{RRM}_{\mathrm{s}}\right)$ have been used effectively to inhibit IKK by antagonizing AP-1 to inhibit proliferation $[35,36]$. Bayon, et al. reported that activity of retinoids and $\mathrm{RRM}_{\mathrm{s}}$ were not same in vitro and intact cells. Intact cell lines expressed weak activity in comparison to in- vitro studies to induce apoptosis and prevent proliferation in cancer lines suggesting RAR independent mechanism in few cancers [10].

Angiogenesis and neovascularization are important motifs which promote proliferation and metastasis of tumor. Angiogenesis is a known predisposing factor to support the survival of neoplastic cells. It is present in all types of head and neck cancers with increased expression of VEGF. Head and Neck Squamous Cell Carcinomas (HNSCC) produce Monocyte Chemotactic Protein-1 (MCP-1) to release TNF- $\beta$ via the production of Interleukin (IL- $1 \alpha$ ) to stimulate secretion of VEGF. Riedel F, et al. observed increased expression of VEGF in HNSCC in mice that has shown decrease in endothelial cell proliferation and migration with VEGF antisense oligonucleotide treatment [37]. L.Strauss also observed complete resolution of tumors related to head and neck region in mice and significant decrease in values of VEGF-A and MCP-1 with RA treatment [38].

Other associated factors required in progression of cancer is TGF- $\alpha$ and Epidermal Growth Factor (EGFr) which was reported to increase in HNSCC when compared to normal mucosal samples collected by Rubin, et al. He reported that retinoids decrease the gene transcription by downregulating the TGF- $\alpha$ and EGFR mRNA levels [39].

\section{Anti proliferative activity}

Fate and Prognosis of the disease is influenced by size, site, stage and type of tumor growth. The outcome is also dependent on molecular expression like, Preferentially Expressed Antigen in Melanoma (PRAME), which is seen to be present in most of the tumors. PRAME triggers cytotoxic $\mathrm{T}$ cell mediated immune response in melanoma and in other solid tumors like HNSCC. Epping MT, et al. reported that PRAME is negatively or weekly expressed in normal tissue but its presence is exponentially related to the stage of tumorogenesis. The direct mechanism of involvement of PRAME is still unknown but it might prevent ligand-receptor activation of retinoids by acting as an antagonist which allows growth of tumor cells and differentiation of malignant stem cells. It also makes the tumor growth unresponsive to treatment with RA, thereby explains the failure of RA treatment in malignant and premalignant lesions in the literature [40].

PRAME act as co-repressor of retinoid signaling pathway. Epping MT, et al. suggested that patient selected for retinoid therapy should be screened for PRAME expression to get maximum benefit with retinoids as a chemopreventive drug. In various studies, patient with strong PRAME expression is treated with either Small Interfering RNA (siRNA) or with lentivirus particles which block binding of PRAME with retinoid receptor so as to improve treatment outcomes [40]. Szczepanski, et al. reported improved outcomes in PRAME negative patient for RA trials, where it inhibit tumor growth, induce apoptosis and decrease EGFR expression to improve overall outcome [41].

\section{Leukoplakia/ Epithelial Dysplasia}

Leukoplakia/ Dysplasia is a pre-cancerous lesion of proliferating basal and suprabasal cells of epithelium associated with a malignant transformation rate as high as $43 \%$. Use of tobacco and allied products are known extrinsic factors to incite the disease [6]. While Ramaswamy G, et al. studied the association of intrinsic factors which showed decreased plasma levels of vitamin $A, B_{12}, C, \beta$ carotene, and folic acid in patients with oral leukoplakia as a common finding [42].

Cessation of habit along with Vitamin A supplements has synergistic effects to control variable degree of epithelial dysplasia. Meir, et al. observed that loss of RAR $\beta$ mRNA as a result of hypermethylation in premalignant lesions may be restored by application of 13 cis RA [6,43,44]. Use of antioxidants like vitamin A block the generation of reactive oxygen species which further prevent normal cell to undergo genetic aberration thereby may revert the tissue to normal state [6]. In premalignant lesions, alteration in p53 molecule result in long half life which does not allow physiological process of cell death leading to frank malignancies [45].

Beenken, et al. observed that pre treatment levels of TGF $\alpha$ and EGFr expression was significantly increased in dysplastic tissue as compared to normal mucosa. He also reported the decrease in its expression following treatment with retinoids, 
which decreased gene transcription by reversing the altered TGF $\alpha$ and EGFr mRNA $[39,46]$.

Retinoids acts via RAR $\beta$ and RXR to prolong the G1 phase of cell division which is blocked by inhibitors of proteasomedependent degradation pathway. The G1- S phase extension help in the repair of altered cell DNA by suppressing cyclin D1 and Cyclin E. It selectively promotes growth suppression or apoptosis of altered epithelial cells in G1 phase and allow repaired cells to carry on to the next phase of cell cycle. In bronchial preneoplasia, ubiquitination of cyclin D1 is a corner stone in cell differentiation that helps G1 phase cell arrest in bronchial epithelium, hence suggesting the role of cyclins as a useful marker to access the aberrant changes in epithelium [47].

Various studies have been conducted with 13 cis RA as a preferred drug of choice for treatment in epithelial dysplasia. It has been observed that complete clinical resolution was variable ranging from $20 \%$ to $87 \%$ with recurrence rate as high as $18 \%[48,49,50]$. Scardina, et al. observed the effects of $0.18 \%$ isotretinoin on patients with epithelial dysplasia and observed $85 \%$ complete resolution in epithelial dysplasia and reduction in size of the lesion clinically [51]. Concentration of vitamin A and its analogs is severely decreased due to utilization of antioxidants by the affected tissue leading to excessive oxidative stress in circulation. Gupta et al have observed that pro Vitamin A act as non enzymatic antioxidants which scavenge lipid per oxidation by products in oral mucosa [52].

Vitamin A can exert its effects when initial signs and symptoms are noted, but once the disease process is advanced, no satisfactory results could be obtained solely. At present, further studies are still under research to estimate the effect of Vitamin A at molecular level following treatment.

\section{Oral Lichen Planus}

OLP is an autoimmune disease affecting the oral mucosa, skin, nails and genital mucosa. It has tendency for malignant transformation to SCC in about 1-2\% of effected patients [53]. It is characterized by the presence of inflammatory mediators like cytokines which interact between keratinocytes and $\mathrm{T}$ lymphocytes [54]. It is postulated that aberrant productions of the cytokines result in gene dysregulation that may cause auto immune reactions resulting in apoptosis of basal cells. Increased expression of Major Histocompatibility Complex (MHC) class II antigen, human leukocyte antigen DR and variable degree of epithelial thickness are underlying features of disease [55].

Deficiency of Vitamin A favors reprogramming of Treg cells into IL-17 which lead to inflammation in autoimmune disorders. RA treatment regulates Th 17 synthesis by inhibiting IL which influences Treg cells to regulate peripheral tolerance [56].

RA also has a tendency to maintain the phenotype and plasticity of Treg cell production in controlling a disease. Local micro- environmental changes also influence the production of cytokines which may be controlled by introducing Vitamin A at early stages to reverse the pathogenesis. Piatelli, et al. observed the effectiveness of 13 cis RA in OLP by assessing expression of Ki 67 and $\mathrm{Bcl}_{2}$ which has shown significant improvement following treatment [55].

Mastrangelo, et al. has also successfully shown improvement in the clinical and microscopic quality of epithelium with 13 cis RA by viewing and comparing pre and post treatment tissue samples under SEM. He also mentioned the role of RA in reversal of pathological state through morphostructural assessment of keratinocyte though relapse was common phenomenon present in both the studies [57].

\section{Squamous cell carcinoma}

Carcinoma is a complex multistep disease that involves genetics and environmental factors to cause initiation, progression and metastasis. The known evidence suggest that proliferative capacity of stratified squamous epithelium is limited to basal and parabasal layer where as the maturation of the cell is the sequential process of terminal differentiation maintained through check points at different levels to suppress the initiation of disease. Promoter methylation, point mutation or homozygous deletion activate tumor suppressors like P16 and p21 which downregulates expression of epithelial differentiation and promote tumorogenesis by reducing growth arrest, cellular senescence and tumor suppression. Crowe DL observed negative expression of p16 and p21 in SCC cell lines confirming that there occurs alteration in cell maturation morphologically that fail to express differentiation at superficial layers $[58,59]$.

Sensitization of p16 and p21 expression can be restored by reactivating RAR $\beta$ which further suppress the tumor growth by screening cells in G1 phase of cell cycle. It has also been confirmed that induction of RAR $\beta$ can instigate terminal differentiation of the mutated cell by specific cell cycle regulatory genes via Cyclin Dependent Kinase (CKIs) [60,61]. Crowe DL observed absence of apoptotic bodies in proliferating epithelium. Presence of squamous following retinoid therapy suggested role of terminal differentiation of the physiologically maturating epithelial cell [58].

Angiogenesis, a nutritive source is maintained by IL- 8 and TGF $\beta$ in neoplastic lesions. Retinoid treatment has showed its effectiveness by suppressing angiogenesis in vitro via neutralization of IL-8 concentration in oral cancer cells. In contrast, TGF $\beta$ shows biphasic role with varying expression in oral cancers. Low levels of retinoids can stimulate the endothelial cell growth by activation of TGF $\beta$ while at high concentration it has a tendency to inhibit the same. It is also suggested that the anti-angiogenesis might be due to the combination of RA induced endothelial cell responsiveness and macrophages mediated angiogenesis. Lingen, et al. concluded that the property of retinoids that lead to anti-angiogenesis is reversible in nature showing waning effects on withdrawal [62].

Gap Junctional Intercellular Communication (GJIC) is considered to regulate tissue independence and homeostasis in multicellular organisms by balancing the growth of GJIC- 
connected cells. Gap junction channels are composed of connexin molecule and connexin genes which show aberrant changes in malignancies. There is lack of cell to cell adhesiveness due to localization of connexins allowing cell independency and growth. Rudkin, et al. showed that retinoids have a tendency to inhibit the cell growth and GJIC- connected cells in HNSCC. The controversy lies whether the time span required by retinoids to repair and revert the cell is at par with the mutated cells undergoing proliferation to produce positive clinical outcome still exist [63].

The potentially malignant oral lesions at high risk of transition to malignancy, if identified, can be effectively managed by early intervention. Chemoprevention using retinoids (RAs) (analogs of vitamin A) is a promising strategy under clinical trials for primary prevention (DiPaola. et al, 1999; Gravis. et al, 1999). Retinoids exert their pleiotropic effects by binding to nuclear receptors in cells and causing inhibition of cell proliferation, modulation of cell differentiation and enhancement of apoptosis (Sidell, et al. 1991; Horn, et al. 1996). Two families of nuclear receptors, the retinoic acid receptor isotypes (RARa, RAR band RARc) and the retinoid $\mathrm{X}$ receptor isotypes (RXRa, RXR band RXRc) are implicated in the transduction of the RA signal (Leid,Kastner and Chambon, 1992; Allenby, et al. 1993; Chambon, 1996). Alterations in the expression of specific receptors could abrogate the retinoidsignaling pathway and may be implicated in carcinogenesis.

\section{Miscellaneous}

In melanoma cells, ATRA has shown its effects on mitochondria to promote apoptosis which is initiated with the release of caspase activating proteins such as cytochrome $\mathrm{C}$ to the cytosol. It occurs by triggering any of the two pathways, thereby suggesting chemopreventive action of RA on melanoma cells [64].

In Promyelocytic Leukemia (PML), Polycomb Gene (PcG) protein silences the tumor suppressor gene to allow tumor growth. RA interacts with PcG protein in a functional antagonistic relationship to promote differentiation of leukemic promyelocytes to granulocytes. It is further associated with PMLRAR $\alpha$ fusion protein leading to remission. It has been observed that $85 \%$ remission obtained by the use of tretinoin with disappearance of blast cell $[2,65]$.

In prostate cancer, activation of TMPRSS2- ERG protein along with PcG protein occurs to promote disruption of lineage specific differentiation [65]. Also RA interacts with androgen in prostate cancer thereby controlling tumorogenesis [66].

In breast cancer, RA can induce re-differentiation of transformed epithelial cell. RA also aid by regulating HOXA5 via RAR- $\beta$ and by controlling cell cycle gene Btg2 to control tumor proliferation and selective apoptosis $[67,68]$. Tumors like superficial bladder tumor, neuroblastoma and glioblastoma have also shown positive results [69].

\section{Epigenetics of resistance in treatment}

Resistance of disease to treatment is still a major setback involving unknown facets. It is common phenomenon to develop resistance against retinoids leading to frequent recurrences or relapse on drug withdrawal. Usually, RAR $\beta$ expression is absent or silenced which prevent heterodimer formation that blocks the classical pathway in solid tumors. Absence of the ligand dependent heterodimers causes failure of treatment in carcinoma using RA. Presence of mutated cancer cell can also lead to treatment failures as a result of conformational de-arrangement of retinoid receptor that easily overcome inhibition by targeted therapy. Literature also suggest that concentration of RA inside the cell hold a key to regulate gene transcription which is usually influenced by either increased metabolism or decrease availability of $\mathrm{RA}^{[70,71,72]}$. This might occur due to rapid metabolism of RA by CYP26, which in turn do not allow RA inside the cell for desirable time. A role of increased CRABP is suggested which sequester the available RA rapidly [73,74]. On the other hand, Budhu and Noy in 2002 suggested reverse hypothesis of CRABP stating that decreased methylation of CRABP-1 promoter can render tumor resistant to RA [75]. In contrast, Marill, et al. stated that cellular resistance is possible due to increased concentration of RA for a prolonged period of time [73].

Zhou DC, et al. observed no clear co-relation between CRABP and RA resistance in cell [76]. It is also suggested that P-gylcoprotein decrease the attained concentration of RA intracellularly by immediate or early flushing [77]. Latest hypothesis about resistance to RA state that point mutation in ligand binding domain of RAR- $\alpha$ might be associated with relapse in Acute Promyelocytic Leukemia (APL) cells $[78,79,80]$. Intrinsic retinoid resistance is also suggested to be lined with free oxygen species present inside the cell which tend to inhibit cell metabolism [81].

\section{Future Perspective}

Extensive research is being conducted to know the vast usefulness of the molecule as a chemotherapeutic drug, though promising results are seen in leukemia and high risk breast cancerous lesion but its usefulness in treating epithelial premalignant and malignant lesion is still under question.? The effective use of chemoprevention may decrease the potential malignant transformation but it is yet to be authenticated by long term studies to analyze the effectiveness of retinoids following treatment. Moreover, we still stand deficient to identify the targeted receptor which maintain inter and intra celluar homeostatsis. Invent of targeted markers can give a promising scope to understand the molecular bases of Vitamin A therapy. Research should focus on retinoid molecules that can delay metabolism of RA inside the cell like RAMBA (Retinoic Acid Metabolism Blocking Agents). Subsequent use of DNA MethylTranferase (DNMT) inhibitors and Histone DeAcetylace (HDAC) inhibitors should be encouraged to revive the expression of lost RAR $\beta$ expression in tumors. Validation of treatment to therapy must be viewed using latest biomarkers to overcome undue exposure in resistant cases. More clinical studies are needed in this direction for treating epithelial malignancies using retinoids as a targeted epigenetic approach to therapy. 


\section{References}

1. Bodhade AS, Dive AM. Chemoprevention of premalignant and malignant lesions of oral cavity: Recent trends. Eur J Dent 2013;7(2):246-50. doi: 10.4103/1305-7456.110198.

2. Bollag W, Holdener E. Retinoids in cancer prevention and therapy Annals of oncology.1992; 3:513-526. Ann Oncol. 1992;3(7):513-26.

3. Sporn MB, Dunlop NM, Newton DL, Smith JM. Prevention of chemical carcinogenesis by vitamin A and its synthetic analogs (retinoids). Fed Proc. 1976;35(6):1332-8.

4. Bennasir H, Sridhar S, Abdel-Razek TT. Vitamin A- From physiology to disease prevention. International Journal of Pharmaceutical Sciences Review and Research. 2010;1(1):68-73.

5. Kronmiller JE, Beeman CS, Nguyen T, Berndt W. Blockade of the initiation of murine odontogenesis in vitro by citral, an inhibitor of endogenous retinoic acid synthesis. Arch Oral Biol. 1995;40(7):645652.

6. Gorsky M, Epstein JB. The Effect of Retinoids on Premalignant Oral Lesions Focus on Topical Therapy. Cancer. 2002;95(6):1258-64.

7. Carratù MR, Marasco C, Mangialardi G, Vacca A. Retinoids: novel immunomodulators and tumour-suppressive agents? Br J Pharmacol. 2012;167(3):483-92. doi: 10.1111/j.1476-5381.2012.02031.x.

8. Heyman RA,Mangelsdorf DJ, Dyck JA, Stein RB, Eichele G, Evans RM,et al. 9-cis retinoic acid is a high affinity ligand for the retinoic acid $\mathrm{X}$ receptor. Cell. 1992;68(2):397-406.

9. Blomhoff R, Green MH, Berg T Norum K. Transport and storage of vitamin A. Science 1990:Vol.250,Issue4979,pp.399-404. DOI: $10.1126 /$ science. 2218545

10. Bayon Y, Ortiz MA, Lopez-Hernandez FJ, Karin M, Pfahl M, Feng Gao,et al. Inhibition of $\mathrm{I} \kappa \mathrm{B}$ Kinase by a New Class of RetinoidRelated Anticancer Agents That Induce Apoptosis. doi: 10.1128/ MCB.23.3.1061-1074.2003Mol. Cell. Biol. 2003vol.23no3:1061-1074

11. Papi A, Guarnieri T, Storci G, Santini D, Ceccarelli C, Taffurelli M, et al. Nuclear receptors agonists exert opposing effects on the inflammation dependent survival of breast cancer stem cells. Cell death and differentiation. 2012;19(7):1208-1219.

12. Lu TY, Li WC, Chen RY, Fan QX, Wang LX, Wang RL, et al. Inhibition effects of all transretinoic acid on the growth and angiogenesis of esophageal squamous cell carcinoma in nude mice. Chinese medical journal. 2011;124:2708-2714.

13.Xu Q, Kopp JB. Retinoid and TGF- $\beta$ families: Crosstalk in development, neoplasia, immunity and tissue repair. Seminars in Nephrology. 2012 ;32(3):287-294.

14. Connolly RM, Nguyen NK, Sukumar S. Molecular Pathways: Current Role and Future Directions of the Retinoic Acid Pathway in Cancer Prevention and Treatment. Clin Cancer Res. 2013;19(7):1651-1659.

15. Burg BVD, Leede B-JMVD, Kwakkenbos-Isbrücker L, Salverda S, Laat SWD, Saag PTVD. Retinoic acid resistance of estradiol-independent breast cancer cells coincides with diminished retinoic acid receptor function. Molecular and Cellular Endocrinology. 1993;91(1-2):14957.

16. Bastien J, Rochette-Egly C. Nuclear retinoid receptors and the transcription of retinoid-target genes. Gene. 2004;328:1-3216.

17. Gupta S, Bi R, Su K, Yel L, Chiplunkar S, Gollapudi S. Characterization of naive, memory and effector CD8 T cells: effect of age. Experimental
Gerontology. 2004;39(4):545-550.

18. Sansoni P, Vescovini R, Fagnoni F, Biasini C, Zanni F, Zanlari L, et al. The immune system in extreme longevity. Experimental Gerontology. 2008;43(2):61-65.

19. Kinoshita K, Kishimoto K, Shimazu H, Nozaki Y, Sugiyama M, Ikoma $\mathrm{S}$, et al. Successful treatment with retinoids in patients with lupus nephritis. American Journal of Kidney Diseases. 2010;55(2):344-347.

20.Wasserfall C, Atkinson MA. Taking a daily vitamin to prevent type 1 diabetes? Diabetes. 2008;58(1):24-25.

21. Mecocci P, Polidori MC, Troiano L, Cherubini A, Cecchetti R, Pini G, et al. Plasma antioxidants and longevity: a study on healthy centenarians. Free Radical Biology and Medicine. 2000;28(8):1243-1248.

22. Szondy Z, Reichert U, Fesus L. Retinoic acids regulate apoptosis of T lymphocytes through an interplay between RAR and RXR receptors. Cell Death and Differentiation. 1998:5(1);4-10.

23. Duke RC, Cohen JJ. IL-2 addiction: withdrawal of growth factor activates a suicide program in dependent T Cells. Lymphokine Res. 1986;5(4):289-298.

24. Yang E and Korsmeyer SJ. Molecular thanatopsis: a discourse on the bcl-2 family and cell death. Blood 1996;88(2):386-401.

25. Dhein J, Walczak H, Baumler C, Debatin K-M, Krammer PH Autocrine T-cell suicide mediated by APO-1/(Fas/CD95) Nature. 1995;373(6513):438-441.

26.Zheng L,Fisher G, Miller RE, Peschon J, Lynch DH, Lenardo MJ. Induction of apoptosis in mature $\mathrm{T}$ cells by tumor necrosis factor. Nature. 1995;377(6547):348-351.

27. Iwata M, Mukai M, Nakay Y, Iseki R. Retinoic acid inhibits activationinduced apoptosis in T-cell hybridomas and thymocytes. J. Immunology. 1992;149:3002-3008.

28. Yang Y, Vacchio MS, Ashwell JD. 9-cis retinoic acid inhibits activation driven T-cell apoptosis: implications for retinoid $\mathrm{X}$ receptor involvement in thymocyte development. Proc. Natl. Acad. Sci. 1993;90(13):6170-6174

29. Yang Y, Bailey J, Vacchio MS, Yarchoan R, Ashwell JD. Retinoic acid inhibition of ex vivo human immunodeficiency virusassociated apoptosis of peripheral blood cells. Proc. Natl. Acad. Sci. 1995;92(7):3051-3055

30. Pohl J, LaFace D, Sands JF. Transcription of retinoic acid receptor genes in transgenic mice increases CD8 T-cell subset. Mol Biol Rep. 1993;17(2):135-142.

31. Altucci L, Gronemeyer H. The promise of retinoids to fight against cancer. Nat Rev Cancer. 2001;1(3):181-193

32. Freemantle SJ, Dragnev KH, Dmitrovsky E. The retinoic acid paradox in cancer chemoprevention. Journal of the National Cancer Institute. 2006;98(7):426-427.

33. Ross AC, Zolfaghari R. Cytochrome P450s in the Regulation of Cellular Retinoic Acid Metabolism. Annu Rev Nutr. 2011;31(1):65-87.

34. Chang CL, Hong E, Lao-Sirieix P, Fitzgerald RC. A novel role for the retinoic acid-catabolizing enzyme CYP26A1 in Barrett's associated adenocarcinoma. Oncogene. 2007;27(21):2951-2960.

35. Chen Z, Hagler J, Palombella VJ, Melandri F, Scherer D, Ballard D,et al. Signal-induced site-specific phosphorylation targets I kappa B alpha to the ubiquitin-proteasome pathway. Genes \& Dev. 1995;9(13):1586- 
1597.

36. Didonato J, Mercurio F, Rosette C, Wu-Li J, Suyang H, Ghosh S, et al. Mapping of the inducible IkappaB phosphorylation sites that signal its ubiquitination and degradation. Mol. Cell. Biol. 1996;16(4):12951304.

37. Strauss L, Volland D, Guerrero A, Reichert T. Antiangiogenic and anti-immunosuppressive therapeutic strategies in human head and neck squamous cell carcinoma (HNSCC). Mund Kiefer Gesichtschir. 2005;9(5):273-281.

38. Strauss L, Volland D, Guerrero A, Reichert T. Antiangiogenic and anti-immunosuppressive therapeutic strategies in human head and neck squamous cell carcinoma (HNSCC). Mund Kiefer Gesichtschir. 2005;9(5):273-281.

39. Grandis JR, Zeng Q, Tweardy DJ. Retinoic acid normalizes the increased gene transcription rate of TGF-alpha and EGFR in head and neck cancer cell lines.Nat Med. 1996;2(2):237-240.

40. Epping MT, Wang L, Edel MJ, Carlee L, Hernandez M, Bernards R. The human tumor antigen PRAME is a dominant repressor of retinoic acid receptor signaling.Cell. 2005;122(6):835-847.

41. Szczepanski MJ, Deleo AB, Łuczak M, Molinska-Glura M, Misiak J, Szarzynska B, et al. PRAME expression in head and neck cancer correlates with markers of poor prognosis and might help in selecting candidates for retinoid chemoprevention in pre-malignant lesions. Oral Oncology. 2012;49(2):144-151.

42. Rajendran R. Oral leukoplakia (leukokeratosis): Compilation of facts and figures. J Oral MaxillofacPathol. 2004;8(2):58-68.

43. Hayashi K, Yokozaki H, Goodison S, Oue N, Suzuki T, Lotan R, et al. Inactivation of retinoic acid receptor $\beta$ by promoter $\mathrm{CpG}$ hypermethylation in gastric cancer. Differentiation. 2001;68(1):1321.

44. Nakayama T, Watanabe M, Yamanaka M, Hirokawa Y, Suzuki H, Ito $\mathrm{H}$, et al. The Role of Epigenetic Modifications in Retinoic Acid Receptor $\beta 2$ Gene Expression in Human Prostate Cancers. Lab. Invest. 2001; 81(7):1049-1057.

45. Curtin JC, Dragnev KH, Sekula D, Christie AJ, Dmitrovsky E, Spinella MJ. Retinoic acid activates p53 in human embryonal carcinoma through retinoid receptor-dependent stimulation of p53 transactivation function. Oncogene. 2001;20(20):2559-2569.

46. Beenken SW, Sellers MT, Huang P, Peters G, Krontiras H, Dixon P, et al. Transforming growth factor alpha (TGF- $\alpha$ ) expression in dysplastic oral leukoplakia: Modulation by 13 -cis retinoic acid. Head Neck 1999;21(6):566-573.

47. Dragnev KH, Rigas JR, Dmitrovsky E. The retinoids and cancer prevention mechanisms. The Oncologist. 2000;5(5):361-368.

48. Kaugars GE, Silverman S, Lovas JG, Thompson JS, Brandt RB, Singh VN. Use of antioxidant supplements in the treatment of human oral leukoplakia: review of the literature and current studies. Oral Surgery, Oral Medicine, Oral Pathology, Oral Radiology, and Endodontology. 1996;81(1):5-14

49. Toma S, Mangiante P, Margarino G, Nicolo G, Palumbo R. Progressive 13-cis-retinoic acid dosage in the treatment of oral leukoplakia. European Journal of Cancer B: oral oncology. 1992;28(2):121-123.

50. Shah JP, Strong EW, Decosse JJ, Itri L, Sellers P. Effect of retinoids on oral leukoplakia, The American Journal of Surgery. 1983;146(4):466470.
51. Scardina G, Messina P, Maresi E. Evaluation of the clinical and histological effectiveness of isotretinoin in the therapy of oral leukoplakia-ten years of experience: Is management still up to date and effective? Methods and Findings in Experimental and Clinical Pharmacology, 2006;28(2):115-119.

52. Gupta S, Reddy MV, Harinath BC. Role of oxidative stress and antioxidants in aetiopathogenesis and management of oral submucous fibrosis. Indian J Clin Biochem. 2004;19(1):138-141.

53. Georgakopoulou EA, Achtari MD, Achtaris M, Foukas PG, Kotsinas A. Oral Lichen Planus as a Preneoplastic Inflammatory Model, Journal of Biomedicine and Biotechnology. 2012;2012:1-8.

54. Lu R, Zhang J, Sun W, Du G, Zhou G. Inflammation-related cytokines in oral lichen planus: an overview. J Oral Pathol Med. 2015;44(1):1-14.

55. Piattelli A, Carinci F, Iezzi G, Perrotti V, Goteri G, Fioroni M et al: Oral lichen planus treated with 13-cis-retinoic acid (isotretinoin): Effects on the apoptotic process. Clin Oral Investig. 2007;11(3):283-288.

56. Tejón G, Manríquez V, Calisto JD, Flores-Santibáñez F, Hidalgo Y, Crisóstomo N, et al. Vitamin A Impairs the Reprogramming of Tregs into IL-17-Producing Cells during Intestinal Inflammation. BioMed Research International. 2015;2015:1-8.

57. Mastrangelo F, Dolci M, Stuppìa L, Paolantonio M, Salini L, Zizzari V, et al. SEM analysis of oral lichen planus before and after treatment with 13 cis-retinoic acid. Int J Immuno pathol Pharmacol. 2007;20(1):7579.

58. Crowe DL. Retinoic acid receptor $\beta$ induces terminal differentiation of squamous cell carcinoma lines in the absence of cyclin-dependent kinase inhibitor expression. Cancer Res. 1998;58:142-148.

59. Liggett WH, Sewell DA, Rocco J, Ahrendt SA, Koch W, Sidransky D. p16 and pl6 beta are potent growth suppressors of head and neck squamous carcinoma cells in vitro. Cancer Res. 1996;56(18):41194123.

60. Zou CP, Clifford JL, Xu XC, Sacks PG, Chambon P, Hong WK, et al. Modulation by retinoic acid (RA) of squamous cell differentiation, cellular RA binding proteins, and nuclear RA receptors in human head and neck squamous cell carcinoma cell lines. Cancer Res. 1994;54(20):5479-5487.

61. Liu M, Iavarone A, Freedman LP. Transcriptional activation of the humanp21 $1^{\text {WAF1/CIP1 }}$ gene by retinoic acid receptor. J. Biol. Chem. 1996;271(49):31723-31728

62. Lingen MW, Polverini PJ, Bouckt NP. Retinoic Acid Induces Cells Cultured from Oral Squamous Cell Carcinomas to Become AntiAngiogenic. American Journal of Pathology. 1996;149(1)247-258.

63. Rudkin GH, Carlsen BT, Chung CY, Huang W, Ishida K, Anvar B, et al. Retinoids inhibit squamous cell carcinoma growth and intercellular communication. J Surg Res. 2002;103(2):183-189.

64.Zhang H,Satyamoorthy K, Herlyn M, Rosdahl I. All-trans retinoic acid (atRA) differentially induces apoptosis in matched primary and metastatic melanoma cells - a speculation on damage effect of atRA via mitochondrial dysfunction and cell cycle redistribution. Carcinogenesis. 2003;24(2):185-191.

65. Bollag W, Holdener EE. Retinoids in cancer prevention and therapy. Annals of oncology. 1992;3(7):513-526.

66. Li MT, Richter F, Chang C, Irwin RJ, Huang H. androgen and retinoic acid interaction in LNCaP cells, effects on cell proliferation and expression of retinoic acid receptors and epidermal growth factor to 
receptor. BMC Cancer. 2002;2:16.

67. Chen H, Zhang H, Lee J, Liang X, WU X, Zhu T, et al. HOXA5 acts directly downstream of retinoic acid receptor beta and contributes to retinoic acid-induced apoptosis and growth inhibition. Cancer Res. 2007;67(17):8007-8013.

68. Donato LJ, Suh Jh, Noy N. Suppression of mammary carcinoma cell growth by retinoic acid: the cell cycle control gene Btg2 is a direct target for retinoic acid receptor signaling. Cancer Res. 2007;67(2):609-615.

69. Chen MC, Hsu SL, Lin Ho, Yang TY. Retinoic acid and cancer treatment. BioMedicine. 2014;4(4):1-6.

70. Moghal N, Neel BG. Evidence for impaired retinoic acid receptorthyroid hormone receptor AF-2 cofactor activity in human lung cancer. Mol Cell Biol. 1995;15(7):3945-3959.

71. White JA, Beckett-Jones B, Guo Y-D, Dilworth FJ, Bonasoro J, Jones $\mathrm{G}$, et al. cDNA cloning of human retinoic acid-metabolizing enzyme (hP450RAI) identifies a novel family of cytochromes P450(CYP26). Journal of biological chemistry. 1997;272(30):18538-18541.

72. McPherson LA, Woodfield GW, Weigel RJ. AP2 transcription factors regulate expression of CRABPII in hormone responsive breast carcinoma. J Surg Res. 2007;138(1):71-78.

73. Fujii H, Sato T, Kaneko S, Gotoh O, Fujii-Kuriyama Y, Osawa, K et al Metabolic inactivation of retinoic acid by a novel P450 differentially expressed in developing mouse embryos. The EMBO Journal. 1997;16(14):4163-4173.

74. Marill J, Idres N, Capron CC, Nguyen E, Chabot GG. Retinoic acid metabolism and mechanism of action: a review. Curr Drug Metab. 2003;4(1):1-10.

75. Budhu AS, Noy N. Direct Channeling of Retinoic Acid between Cellular
Retinoic Acid-Binding Protein II and Retinoic Acid Receptor Sensitizes Mammary Carcinoma Cells to Retinoic Acid-Induced Growth Arrest. Molecular and Cellular Biology. 2002;22(8):2632-2641.

76.Zhou DC, Hallam SJ, Lee SJ, Klein RS, Wiernik PH, Tallman MS, et al. Constitutive expression of cellular retinoic acid binding protein II and lack of correlation with sensitivity to all-trans retinoic acid in acute promyelocytic leukemia cells. Cancer Res 1998;58(24):57715776.

77. Kizaki M, Ueno H, Yamazoe Y, Shimada M, Takayama N, Muto A, et al. Mechanisms of retinoid resistance in leukemic cells: possible role of cytochrome P450 and P-glycoprotein. Blood. 1996;87(2):725-733.

78. Cote S, Zhou D, Bianchini A, Nervi C, Gallagher RE, Miller WH. Altered ligand binding and transcriptional regulation by mutations in the PML/RAR $\alpha$ ligand-binding domain arising in retinoic acid-resistant patients with acute promyelocytic leukemia. Blood. 2000;96:3200208.

79. Imaizumi M, Suzuki H, Yoshinari M, Sato A, Saito T, Sugawara A Tsuchiya S, Hatae Y, Fujimoto T, Kakizuka A, Konno T, Iinuma K. Mutations in the E-domain of RAR $\alpha$ portion of the PML/RAR $\alpha$ chimeric gene may confer clinical resistance to all-trans retinoic acid in acute promyelocytic leukemia. Blood.1998;92:374-382.

80. Ding W, Li YP, Nobile LM, Grills G, Carrera I, Paietta E, et al. Leukemic cellular retinoic acid resistance and missense mutations in the PMLRAR $\alpha$ fusion gene after relapse of acute promyelocytic leukemia from treatment with all-trans etinoic acid and intensive chemotherapy. Blood. 1998;92:1172-1183.

81. Demary K, Wong L, Liou JS, Faller DV, Spanjaard RA. Redox control of retinoic acid receptor activity: a novel mechanism for retinoic acid resistance in melanoma cells. Endocrinology. 2001;142(6):26002605 . 